\title{
Taking the heat out of global warming
}

\author{
Two 'mainstream sceptics' take a critical look at the majority view.
}

\section{The Satanic Gases: Clearing the Air about Global Warming by Patrick J. Michaels \& Robert C. Balling Jr Cato Institute: 2000.234 pp. $\$ 19.95$ (cloth); $\$ 10.95, \mathfrak{E} 7.99$ (pbk) \\ Hans von Storch}

Everybody knows about climate, and many people blame climate change and anthropogenic emissions for all kinds of weatherrelated catastrophes. In their book, Pat Michaels and Robert Balling accuse the current US president, and one of the candidates for the job, of misusing such fears in their policies. The authors argue that global warming is a scientific construct that owes its survival largely to the conservative reliance on a once-accepted paradigm rather than on rational arguments.

The authors' main motivation for publishing The Satanic Gases seems to have been the imminent US elections. They fear that the science of global warming could be used as a "basis for sweeping policy recommendations that could gravely harm United States prosperity". And they circle around US politics in a way that can be either amusing or annoying for a non-US reader. However, the book is more than this. Once the first parochial sections are dispensed with, one finds the authors' own view of the science of climate.

Michaels and Balling cover a broad range of subjects. They move from a short history of the Intergovernmental Panel on Climate Change (IPCC) to a description of the climate system, the observational climate record and the problems the IPCC has had in coming to grips with the fact that the recent warming has been smaller than the greenhouse theory would have suggested. They even make a quick excursion into the theory of scientific revolution. They give their own best guesses at future climate change and its impact in terms of sea level, mortality, vegetation and agricultural production. Both authors, defining themselves as 'mainstream sceptics', agree with the concept of global warming, but claim that it is at the lower end of the IPCC's spectrum of scenarios.

Their main argument is that, because contemporary climate models show a linear increase in temperature and other variables, the future increase should be a linear extension of these recent trends. Thus, they conclude: "The bottom line is a warming of around $1.5^{\circ} \mathrm{C}$ to $1.7^{\circ} \mathrm{C}$ in the winter half year and $1.2^{\circ} \mathrm{C}$ to $1.3^{\circ} \mathrm{C}$ in the summer over the course of the next century". Since, according to their analysis, winter cold inflicts far more harm than summer heat, they expect the positive impacts of global warming to clearly outweigh the negative impacts. After reading a chapter explaining in some detail the various problems with general-circulation models, which concludes that they are suitable only for theoretical lecture-room studies, I wonder why they believe one particular feature of climate model simulations - the linearity of the temperature increase.

The authors' numerous references to the peer-reviewed literature tend to be biased towards publications giving estimates of a low climate sensitivity. Examples of this include scenarios of North Atlantic storms. And evidence in line with their adopted point of view is uncritically selected from the manifold of palaeoclimatic data. But as the book is a polemic, the evidence put forward seems reasonable, and the critiques raised make one wonder whether the summary of the IPCC Second Assessment Report was possibly also biased. Michaels and Balling find it particularly upsetting that, although the report was published in 1996, it used a crucial 'detection' paper that considered data only up to 1988 , even though, after this time, warming ceased or was even followed by a period of cooling. They emphasize the as-yet unresolved inconsistency between temperature trends at the Earth's surface and those in the mid-troposphere, where there has been no really significant warming in the past 20 years.

The book is not without errors. For instance, it claims that contemporary general-circulation models would not explain mid-latitude storms. And the attempt at a statistical explanation of the link between crop production and the concentration of air-borne carbon dioxide is based on the correlation of two trends, which would always return a high measure of similarity. But such a wide-ranging discussion could not be expected to be error-free.

Is the book worth reading? If you are only ever going to read one book on climate change, then no. Otherwise, it is useful to have a critical assessment of a majority view, and one which is - perhaps too early for its own good - set in stone in the IPCC reports. Climate research is no longer value free. When we questioned some 400 climate scientists from North America and Europe, most acknowledged this fact. Many climate scientists have become activists, promoting subjective policies for improving the world. Some want to do this by reducing greenhouse-gas and other emissions, others by

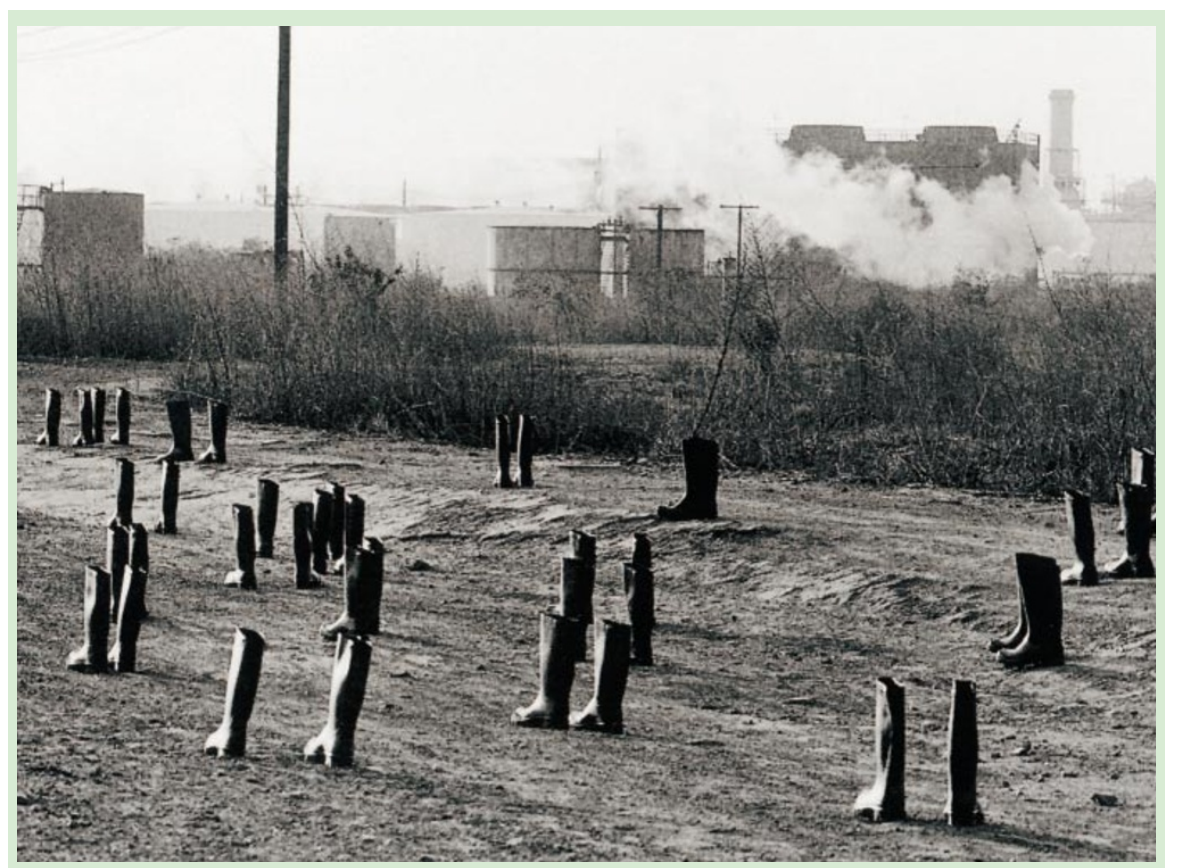

\section{On an industrial footing}

They began as postcards, a pictorial narrative of the America of the Vietnam era. 100 Boots by performance artist Eleanor Antin (Running Press, $£ 12.99)$ is a compilation of the 51 photographs of the boots on the beach, going to church, at the supermarket, at a job (detail above), and going to war. Their final resting place was New York's Museum of Modern Art. 
reducing the concern over a hypothetical future event. Both groups have non-scientific motives in their baggage. At least in Europe, the first group dominates, and it may indeed be very helpful to read what the other faction of scientists have to say.

The book's last section deals with the social process of science, how certain views, such as the probability that global warming will have disastrous effects, become dominating paradigms and how the organization of science may influence this process. These are relevant questions, and research agencies would do well to provide more funding for interdisciplinary research into such matters, particularly if they feed directly into policymaking.

The book is well written and easy to read. And the authors should be applauded for their bold predictions for the future, which will be proven right or wrong by the course of history: the Kyoto Protocol will have no effect; carbon dioxide emissions will continue to increase; by 2050, the Earth's average surface temperature will have increased by $0.65-$ $0.75^{\circ} \mathrm{C}$ in the winter half-year and by between 0.60 and $0.65{ }^{\circ} \mathrm{C}$ in summer; by 2050, crop yields will have risen sufficiently for the (carbon dioxide-related) rise alone to feed one-quarter of today's population; temperature-related mortality will decline.

Others make different forecasts. Hans von Storch is at the Institute of Hydrophysics, GKSS Research Centre, Max-Planck-Strasse 1, PO Box, 21502 Geestacht, Germany.

\section{To the core of consciousness}

\section{A Universe of Consciousness: How Matter Becomes Imagination/ Consciousness: How Matter Becomes Imagination \\ by Gerald Edelman \& Giulio Tononi Basic Books/Allen Lane: 2000. 288 pp. $\$ 27.50 / £ 20$}

\section{Raymond J. Dolan}

A Universe of Consciousness is the latest in a series of books in which the principal author, Gerald Edelman, develops a neurobiological theory of consciousness. It is no exaggeration to say that his previous books have aroused conflicting reactions. A frequent criticism has been that he couches fairly simple ideas in an idiosyncratic jargon that renders the end product impenetrable. Such criticism will be hard to level against the current volume, coauthored by Guilio Tononi, which represents the best and most accessible introduction to Edelman's ideas on consciousness.

A substantial portion of the book goes over familiar ground. In brief, Edelman has championed a view that brain function and organization are determined by Darwinian evolutionary principles that occur within the lifetime of the organism. Consequently, major sections are taken up with accounts of selectionism, the concept of value and the

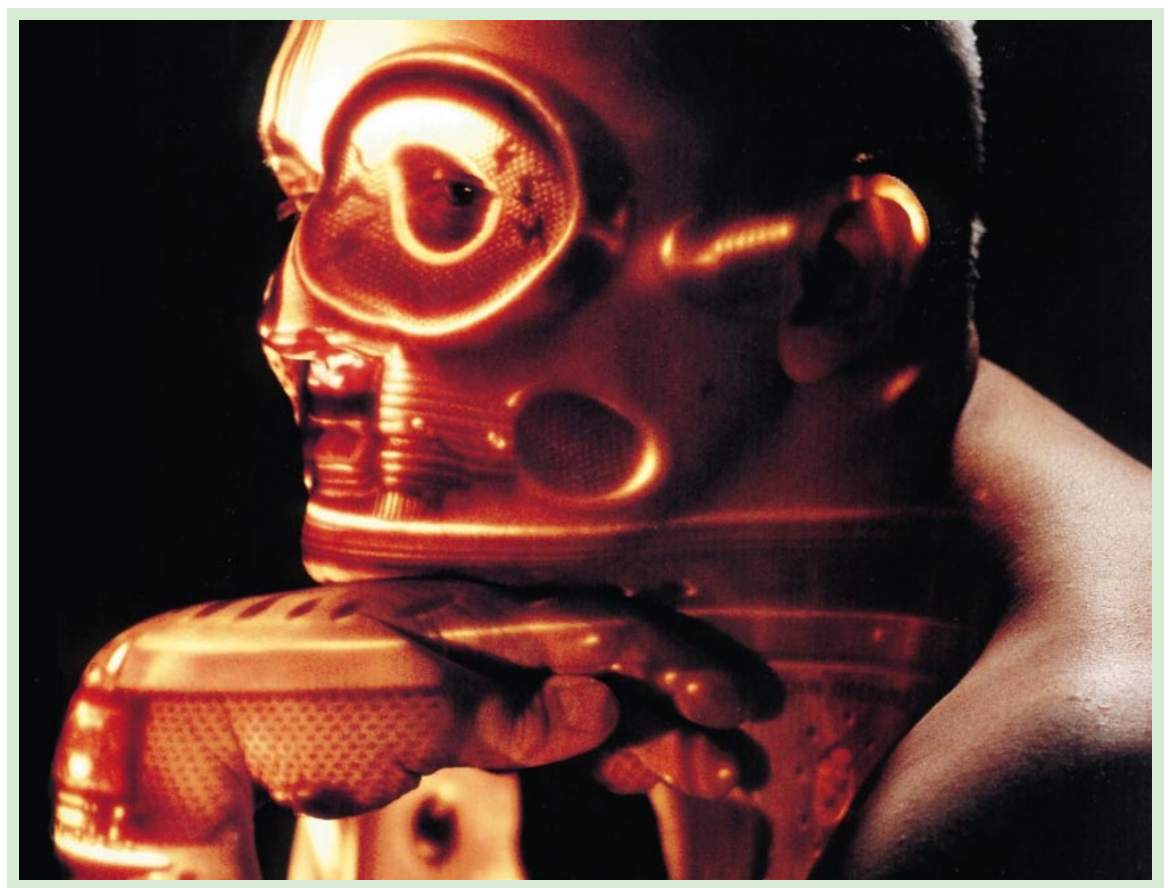

\section{Man made machine?}

Is it possible that we will eventually become robots ourselves, uploading our consciousness into computers? Robo Sapiens: Evolution of a
New Species by Peter Menzel and Faith D’Aluisio (MIT Press, \$29.95, £19.95) shows how far we have come along that path. critical role of neuronal interactions mediated by a process he has labelled re-entry. Reentry is a much misunderstood idea, often confused with feedback. It refers to the dynamic interchange between reciprocally connected brain regions that is fundamental to synchronization and the coordination of their mutual functions.

All of these ideas are treated clearly and concisely. There is also wide acknowledgement of competing ideas on the structure of consciousness and, although it is clear that the main issue is higher-order consciousness, there is an acceptance that a complete account will include what has been termed primary consciousness.

A Universe of Consciousness still provides its moments of frustration. A prime example is the treatment of memory, in which the authors propose the controversial idea that all forms of memory are non-representational - here the authors provide the useful geological metaphor that memory is more like the melting and freezing of a glacier (non-representational) than an inscription on a rock (representational). In their account, memory results from selective matching between distributed neural activity and signals from the world, the body and the brain itself. But this potentially radical proposal is not developed sufficiently.

The book's novel contribution is the development of what is termed the "dynamic core hypothesis". Put simply, a dynamic core is a subset of brain regions identified by the pattern of neuronal interactions within the core and its associated regions. As an analogy, the core can be considered akin to a shoal of fish. The envelope, or boundary, is clearly discernible but continuously changes as the fish (neuronal activity) swim to different locations (different neuroanatomical domains). The fish swim in concert, but each has its own unique trajectory through the water (that is, neuronal activity is coherent but not identical).

Critically, the core is characterized by being functionally disconnected from the rest of the brain. This disconnection is represented by relatively independent neuronal dynamics inside and outside the core. Thus, the authors liken the dynamic core to a functional cluster. The second key idea is that patterns of activity within the core exhibit a high degree of complexity. The complexity of the core is important because it reflects a high degree of differentiation, implicit in observing a particular brain state, given the diversity of patterns that could be expressed. The boundaries that define the core are predicated on constantly changing patterns of activity and are themselves dynamic, reflecting the functional state of the brain.

The notion of a dynamic core is both conceptually appealing and usefully grounded in information theory. There is, however, a problem with it. This arises from the fact that 